\title{
Exploration of the temperature-dependent correlations present in the structural, morphological and electrical properties of thermally reduced free-standing graphene oxide papers
}

\author{
Harihara Ramamoorthy ${ }^{1}$, Kanokwan Buapan ${ }^{2}$, Tinna Chiawchan ${ }^{2}$, Krongtham Thamkrongart ${ }^{2}$, and \\ Ratchanok Somphonsane ${ }^{2,3, \star}$ (i) \\ ${ }^{1}$ Department of Electronics Engineering, Faculty of Engineering, King Mongkut's Institute of Technology Ladkrabang, 1 \\ Chalongkrung Road, Ladkrabang, Bangkok 10520, Thailand \\ ${ }^{2}$ Department of Physics, Faculty of Science, King Mongkut's Institute of Technology Ladkrabang, 1 Chalongkrung Road, \\ Ladkrabang, Bangkok 10520, Thailand \\ ${ }^{3}$ Thailand Center of Excellence in Physics, Commission On Higher Education, 328 Si Ayutthaya Road, Bangkok 10400, Thailand
}

Received: 11 May 2021

Accepted: 14 June 2021

Published online:

1 July 2021

(C) The Author(s) 2021

\begin{abstract}
We report on a corroborative study of the structural, morphological and electrical property alterations of free-standing graphene oxide (GO) papers subject to thermal reduction. Structural analysis performed using Fourier transform infrared spectroscopy (FTIR), X-ray diffraction (XRD) and Raman techniques prove that the onset of major structural changes, characterized by removal of oxygen functionalities, occur in the $200-300{ }^{\circ} \mathrm{C}$ temperature range. The results are corroborated with related morphological changes observed using Scanning electron microscopy (SEM) and Atomic force microscopy (AFM) imaging. Elemental analysis shows the GO paper reduced at $600{ }^{\circ} \mathrm{C}$ to contain an $85 \mathrm{wt}$. \% carbon content and a remnant oxygen level of $13.31 \mathrm{wt}$. \%. At the highest reduction temperatures, we see evidence of vacancy-type defects impeding the overall effectiveness of the reduction process. Detailed electrical resistance measurements and current-voltage (I-V) profiling conducted using four-point probe method reveals a several orders of magnitude drop in the sample resistance once the reduction temperature exceeds $200{ }^{\circ} \mathrm{C}$, in good agreement with the structural and morphological changes. The fundamental insights revealed through these studies will be important for future applications where the electrical and mechanical properties of free-standing GO and reduced graphene oxide (rGO) are exploited in practical devices.
\end{abstract}

Handling Editor: Annela M. Seddon.

Address correspondence to E-mail: ratchanok.so@kmitl.ac.th 


\section{GRAPHICAL ABSTRACT}
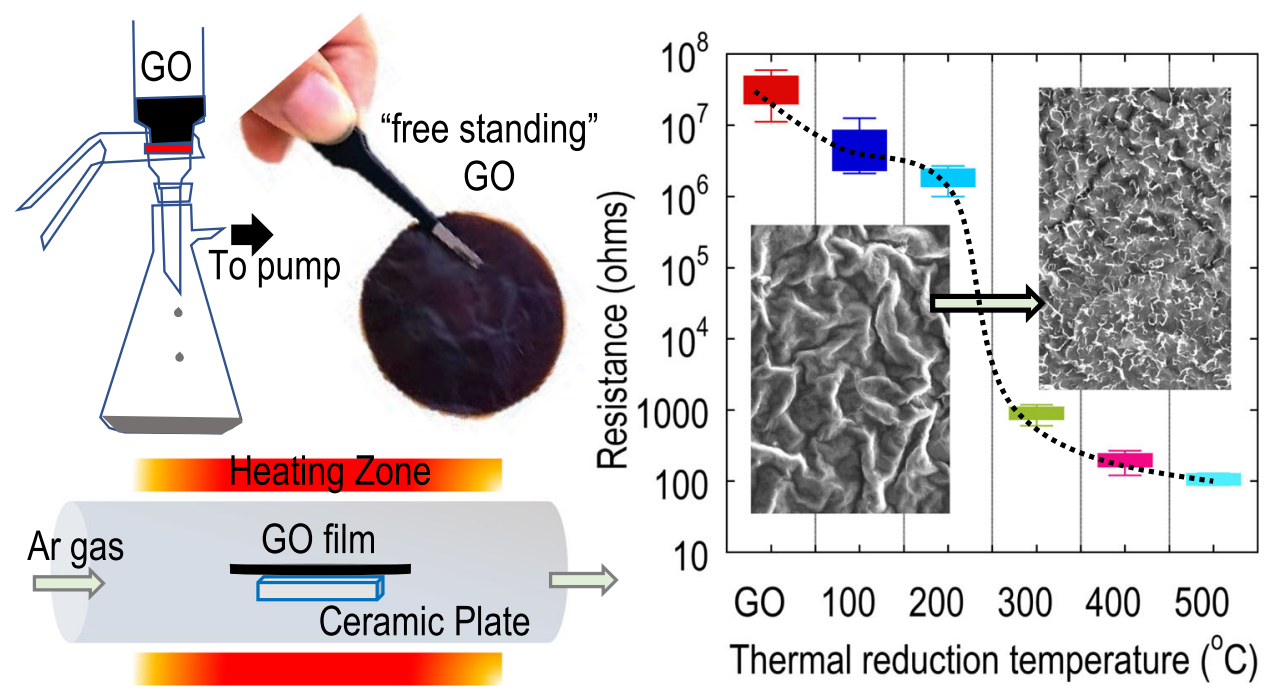

\section{Introduction}

In the past decade, graphene has grabbed a great deal of attention in the 2D materials research community [1,2]. Among the several remarkable properties that this wonder material boasts of are its high mechanical strength, ultra-high mobility of its conducting electrons, efficient thermal conductivity and its surface conformability. While many of these properties pertain to graphene studied in its pristine form, it is worthwhile to note they arise from investigations of micrometer-scale sample sizes that are obtained by the mechanical exfoliation of graphite using the infamous scotch-tape technique [2]. On the contrary, large-scale and pristine graphene have also been successfully realized via bottom-up synthesis techniques such as chemical vapor deposition (CVD) [3-5], but the technique suffers from the associated high-cost and technological challenges of scalability [5]. To circumvent these problems, top-down synthesis routes of graphene alternatives such as reduced graphene oxide (rGO) have been gaining increasing attention in the recent past.

The starting step in the process of obtaining rGO is the synthesis of graphene oxide (GO). GO is obtained through the chemical [6-8] or electrochemical exfoliation $[9,10]$ of graphite, based on methodologies proposed by Hummers [6], Brodie [8] and others [11-13]. More recently, the modified Hummer's method [12, 13] has been accepted as the new standard for obtaining GO solutions, owing to its lower toxicity levels, explosion safety and improved yields. A typical chemical exfoliation process starts by the introduction of strong oxidizers that intercalate the carbon layers in the graphite. This causes a disruption in the crystalline network of $\mathrm{sp}^{2}$ carbon atoms due to the occupation of oxygenated functional groups such as the hydroxyl $(-\mathrm{OH})$, epoxy (-O-), carbonyl $(\mathrm{C}=\mathrm{O})$ and carboxylic $(-\mathrm{COOH})$ groups [14-18]. The GO is therefore rendered defective and highly electrically insulating in comparison to its graphite parent.

Fortunately, these detrimental functional groups may be eliminated by a variety of reduction processes that finally yields $\mathrm{rGO}$, a highly conductive material akin to graphene. A few commonly used routes to achieve this transformation are through reduction via chemical means [19-23], thermal reduction under vacuum [17, 24-26] or other atmospheres [27-29], joule heating assisted reduction [30-32], reduction using microwave radiation [33-36] and by employing a few other novel methods [37-40]. A recent review 
article [41] can be referred to by the reader for a comparative study on the various scalable routes to synthesize rGO. rGO can be processed into various three-dimensional structures such as free-standing rGO papers [42-49], foams [50, 51], gels [52, 53] and as films deposited on desired substrates [54]. The various forms of $\mathrm{rGO}$ are then used in wide ranging applications such as solar cells [55], sensors [56, 57], supercapacitors [58, 59], thin-film conductors [60], membranes [61], water purification [62, 63] and biomedical applications [64]. In particular, scalable and flexible free-standing rGO offers a significant advantage when it pertains to its use in energy storage devices, for instance, as a replacement material for electrodes in supercapacitors $[58,59,65,66]$. This is possible due to the presence of closely stacked graphene layers that provide a high surface area for electron or ion diffusion. Moreover, due to the absence of supporting substrates or other added blending materials, free-standing rGO papers possess superior electrical $[44,67,68]$ and thermal conductivities [45]. The obtained rGO paper may therefore be viewed as a dialed-down version of intrinsic graphene but with the extremely important advantage of being a low-cost alternative that can also be massproduced. For these reasons, it is imperative to comprehensively understand the structural and electrical properties of this material.

Of the various reduction techniques available, thermal reduction offers a very simple and environmentally friendly route to obtain rGO. While a complete elimination of the functionalities is difficult to achieve, as is evident from ab initio studies [69, 70], the reduction process is nonetheless highly effective, and recovers to a large extent, the intrinsic properties of graphene. Additionally, the extent of reduction can be controlled through experiment [71, 72], allowing for a direct means of tuning the different properties such as its thermal or electrical conductivity and solubility.

Despite the apparent advantages of thermal reduction and free-standing rGO, most studies in the literature have focused on the thermal reduction effect on GO that is obtained either in powder form $[27,73,74]$ or via means of drop-casting [75] onto a substrate of choice. There have been only a handful of reports that focuses on the thermal reduction process of free-standing GO papers [42, 45-47]. Systematic studies to determine critical temperatures or crossover behaviors, important for GO-based applications sensitive to high temperatures, have not been reported. Moreover, correlation studies of the temperaturedependent structural and morphological variations and the electrical properties such as the film resistance and current-voltage behavior is still lacking.

In this work, we aim to carry out a comprehensive analysis to understand the evolution of structural, morphological and electrical changes occurring in free-standing GO papers, as a function of reduction temperature. To obtain free-standing GO, we follow a facile vacuum filtration [76, 77] approach that has the advantage of yielding scalable, uniform and large area sheets of the material in thin-film form. The vacuum-filtered GO papers are then subject to thermal reduction to convert them to free-standing rGO papers. The choice of thermal reduction ensures good experimental control and tunability and therefore allows for the reliable and systematic characterization of the samples at various stages of the reduction process.

Structural changes occurring in the GO papers in response to thermal reduction are captured using Fourier transform infrared spectroscopy (FTIR), Raman, X-ray diffraction (XRD) and energy-dispersive $X$-ray spectroscopy (EDX) techniques. FTIR is used to identify the various oxygen functional groups that intercalate the GO layers and qualitatively analyze the change in their compositions as reduction temperature is varied. The extent of disorder is quantified by studying the ratio of the characteristic $D$ and $G$ peaks obtained from the Raman spectroscopy while the dominant crystalline phases and their transformations are identified using XRD. EDX analysis of the film surface reveals the reduction efficiency in terms of the carbon and oxygen content present in the GO papers post reduction. Surface morphological changes are analyzed using scanning electron microscopy (SEM) and atomic force microscopy (AFM). Film thickness and layer exfoliation are studied using cross-sectional SEM imaging and the electrical resistance and current-voltage (I-V) behavior are analyzed using the four-point probe method.

Strong correlations are found between the structural, morphological and electrical properties of the thermally reduced GO papers. Four-point resistance measurements reveal a dominant crossover from an insulating to highly electrically conducting behavior beyond a reduction temperature of $200{ }^{\circ} \mathrm{C}$. The orders of magnitude drop in resistance corroborates well to the onset of major structural changes 
observed from the FTIR, Raman, XRD and EDX analyses. SEM images reveal notable surface morphology changes occurring beyond the crossover temperature. At the highest reduction temperature of $600{ }^{\circ} \mathrm{C}$, the rGO surface is dominated by a grainier appearance which is suggestive of an uptick in vacancy defect formation and signals the occurrence of a bottleneck in the reduction efficiency. Overall, the temperature-dependent correlations identified in this work is expected to be useful for exploitation in practical device applications based on GO and rGO.

\section{Materials and methods}

\section{Chemicals}

The raw materials needed for the preparation of GO suspension included graphite powder ( $99 \%$ purity), hydrogen peroxide $\left(\mathrm{H}_{2} \mathrm{O}_{2}, 30 \%\right)$ obtained from Sigma-Aldrich (USA) and potassium permanganate $\left(\mathrm{KMnO}_{4}\right)$, hydrochloric acid $(\mathrm{HCl}, 37 \%)$ and sulfuric acid $\left(\mathrm{H}_{2} \mathrm{SO}_{4}, 98 \%\right)$ purchased from Merck (Germany). Whatman ${ }^{\mathrm{TM}}$ cellulose nitrate filter papers with $0.2 \mu \mathrm{m}$ pore size and $47 \mathrm{~mm}$ diameter were also purchased from Merck (Germany).

\section{Preparation of graphene oxide (GO) suspension}

Firstly, a GO suspension was prepared following the process previously described by Phrompet et al [78]. In short, graphite powder was oxidized using a modified Hummers' method to obtain graphite oxide. The resulting yellowish-brown product was separated by centrifugation followed by washing in $\mathrm{HCl}$ to remove sulfates. The obtained solution was then filtered and washed several times until a solid paste with $\mathrm{pH}$ value of approximately 7 was obtained, which was then dried in an oven at $65^{\circ} \mathrm{C}$ overnight to obtained powdered graphite oxide. The powder was subsequently re-dispersed in distilled water followed by ultrasonication and centrifugation to finally obtain a dark brown supernatant of aqueous suspension of GO nanosheets with a concentration of $5 \mathrm{mg} / \mathrm{ml}$.

\section{Preparation of free-standing GO papers}

The high dispersion qualities of GO in water makes it a suitable candidate for vacuum filtration. About $2 \mathrm{ml}$ of the aqueous solution of GO was poured through a cellulose nitrate filter paper $(0.2$ microns pore size) fitted to a typical vacuum filtration apparatus shown in Fig. 1b. A vacuum pump producing a constant pressure of minus $650 \mathrm{~mm} \mathrm{Hg}$ causes the solvent molecules to be filtered out through the pores of the membrane filter in a uniform manner. This ultimately results in a well-ordered and layered structure of GO that is left behind. The GO-laden filter paper (Fig. 1c) was then baked on a hot plate at $50{ }^{\circ} \mathrm{C}$ for $30 \mathrm{~min}$ which allowed for the separation and smooth peeling of free-standing GO papers from the filter membrane. The obtained GO papers, having diameter of approximately $40 \mathrm{~mm}$, were then cut into six equal portions for subsequent thermal reduction studies and for the various structural and electrical characterizations. The final GO papers were found to be approximately $5 \mu \mathrm{m}$ thick from cross-sectional SEM images and were compact, mechanically stable and flexible. Given that these qualities are increasingly preferred for achieving improved performance in energy storage devices and electrode materials, a facile, low-cost and environmentalfriendly approach presented here is deemed an ideal candidate.

\section{Thermal reduction of GO paper}

To carry out the thermal reduction process, the GO papers were laid flat on a high purity alumina plate and placed at the center of the heating zone of a tube furnace (Fig. 1d). The thermal annealing profile used in this work is as follows. After the loading of the sample, the tube is purged with high purity $(99.995 \%)$ Ar gas for $15 \mathrm{~min}$ at a gas flow rate of $1000 \mathrm{sccm}$. The flow rate is subsequently lowered to and maintained at $500 \mathrm{sccm}$. The temperature is then ramped to the set value with a constant rate of $10{ }^{\circ} \mathrm{C} / \mathrm{min}$. Once the set temperature is reached, it is allowed to soak for a period of $10 \mathrm{~min}$. The annealing was carried out at various set temperatures ranging from 100 to $600{ }^{\circ} \mathrm{C}$. The heat is then cut off and the sample is allowed to cool down naturally to room temperature before it is unloaded from the furnace. The samples (Fig. 1e) are then stored in a humidity-controlled dry box. 
(b)

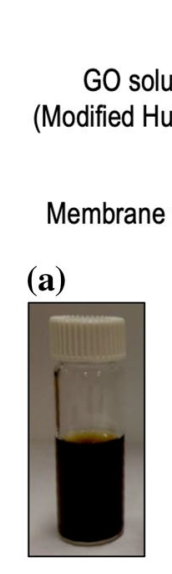

to pump
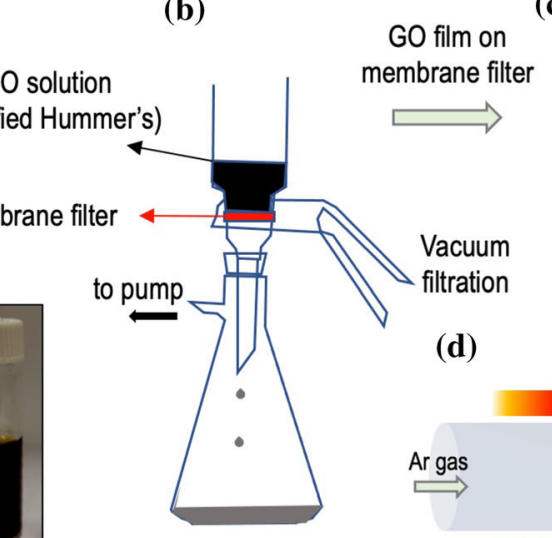

(d) (c)
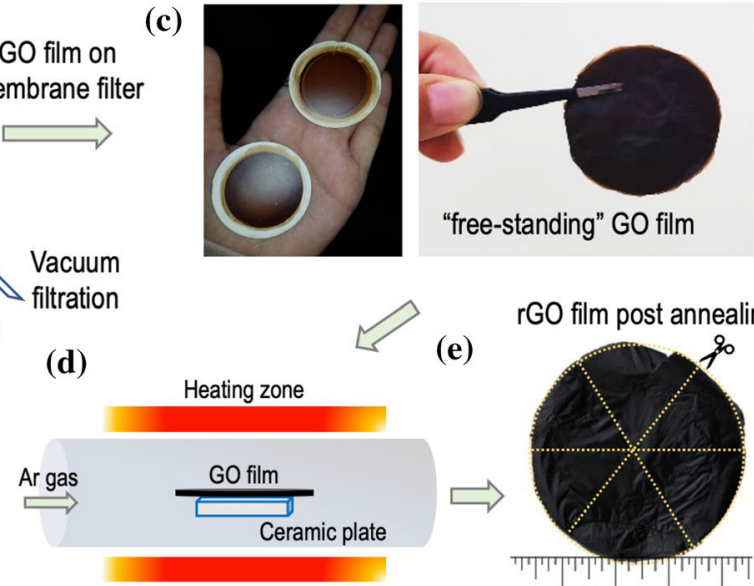

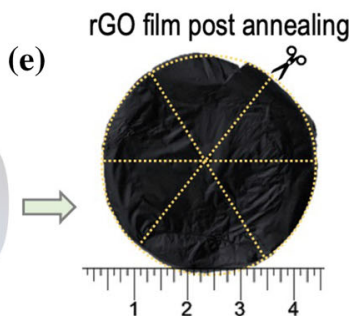

Figure 1 Schematic illustration of the vacuum filtration apparatus and the steps followed to obtain free-standing rGO paper. a GO solution $(5 \mathrm{mg} / \mathrm{ml})$ prepared following steps outlined in Ref 79 . b Schematic of the vacuum filtration apparatus. c GO-laden

\section{Material characterization methods}

The FTIR spectra were recorded in the wavenumber range of $500-4000 \mathrm{~cm}^{-1}$ with a Bruker Senterra system. Dispersive Raman analysis was conducted using DXR Smart (Thermo Scientific) at a laser excitation wavelength of $532 \mathrm{~nm}$. The lattice parameters were studied using Rigaku Miniflex X-ray diffractometer under a $\mathrm{Cu} K_{\alpha}$ radiation of wavelength $1.54 \AA$ and a $2 \theta$ range of $10-80^{\circ}$ and a step size of $0.02^{\circ}$. JSM -5800 LV (JEOL) Field-Emission Scanning Electron Microscope (FESEM) was used to track the changes in surface morphology, film thickness and to obtain the elemental analysis via EDX. Surface roughness was measured using AFM imaging using an AFM workshop TT-2 AFM system. The AFM images were analyzed using the free Gwyddion software package. Electrical resistance measurements were performed using an Everbeing four-point probe measurement system in combination with Keysight sourcemeter (B2901A) and a 6.5 digital Keysight multimeter (34461A).

\section{Results and discussions}

\section{FTIR}

FTIR analysis is a popular technique to determine the presence of functional groups in materials. Figure 2 shows the FTIR traces obtained for the starting GO membrane filter obtained post filtration (left) and after separation from the membrane (right). $\mathbf{d}$ Schematic of the thermal reduction setup. e Final free-standing rGO paper obtained post annealing.

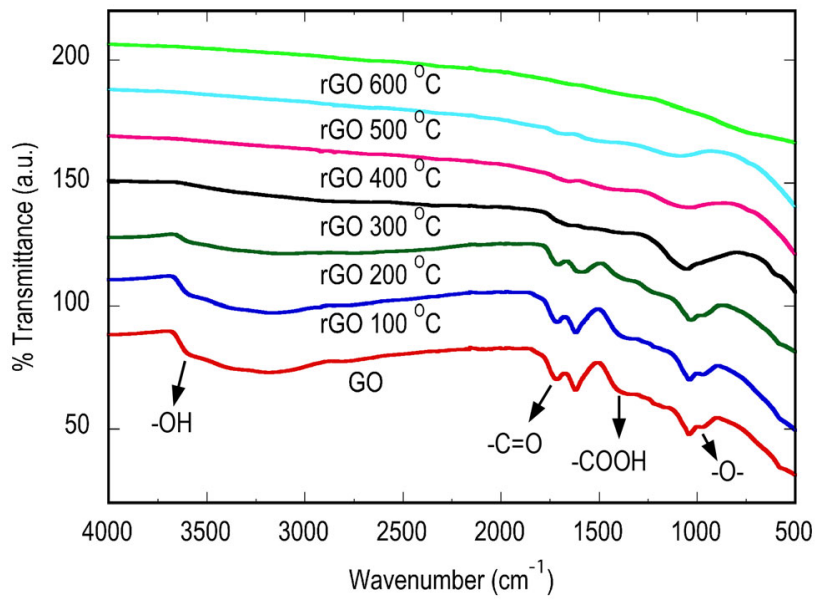

Figure 2 FTIR spectra of the original GO paper and rGO papers obtained after thermal reduction at temperatures of $100{ }^{\circ} \mathrm{C}$, $200{ }^{\circ} \mathrm{C}, 300{ }^{\circ} \mathrm{C}, 400{ }^{\circ} \mathrm{C}, 500{ }^{\circ} \mathrm{C}$ and $600{ }^{\circ} \mathrm{C}$.

paper and the GO papers subject to thermal reduction at several temperatures ranging between 100 and $600{ }^{\circ} \mathrm{C}$. It can be clearly seen that for the original GO paper there are four strong peaks in the transmittance data, which confirms the presence of different oxygenated functional groups. The broad peak seen centered around $3300 \mathrm{~cm}^{-1}$ corresponds to that of the hydroxyl $(-\mathrm{OH})$ group, which clearly flattens at $400{ }^{\circ} \mathrm{C}$. This signifies the complete elimination of the hydroxyl groups from the basal plane of GO at this processing temperature. The second important peak that occurs in the FTIR spectrum is that of the carbonyl 
$(\mathrm{C}=\mathrm{O})$ group, seen at a frequency of roughly $1750 \mathrm{~cm}^{-1}$. This peak is also strongly dampened at $400{ }^{\circ} \mathrm{C}$, but it takes $600{ }^{\circ} \mathrm{C}$ to fully eliminate the functional group. The elimination happens via the expulsion of gases such as $\mathrm{CO}_{2}$ and $\mathrm{CO}$ from the basal planes and are therefore expected to leave carbon atom vacancies (or defects) behind. This is one of the reasons why rGO can seldom match the superior qualities of pristine graphene. On a positive note, such defects have been reported to be beneficial for certain applications such as sensors and energy storage $[79,80]$. The presence of the carboxylic group $(-\mathrm{COOH})$ is confirmed by the third peak at $1400 \mathrm{~cm}^{-1}$, which also gradually disappears as the specimen temperature is increased. The final peak of importance is seen at about $1100 \mathrm{~cm}^{-1}$ and corresponds to the epoxy functional group. Unlike the hydroxyl, carboxy or carbonyl groups which shows signs of peak intensity reduction at lower temperatures, the peak corresponding to the epoxy group is prominent and shows initial signs of weakening only after about $400{ }^{\circ} \mathrm{C}$. This is consistent with earlier reports suggesting that the epoxy groups require higher thermal energy to be dissociated from the lattice [23, 24, 81, 82]. Overall, the FTIR results strongly suggest the presence of oxygenated functional groups in the synthesized GO paper, in agreement with the theoretical models of Lerf [14] and Klinowsky [83]. The systematic weakening and eventual disappearance of the major transmittance peaks with increasing processing temperature confirms the elimination of these functional groups from the GO structure.

\section{Raman spectroscopy}

Structural changes in GO and rGO can be understood by studying the changes in the characteristic D and $G$ peaks obtained from Raman spectroscopy. The D peak is located at $1350 \mathrm{~cm}^{-1}$ and is a signature of aliphatic carbons forming disordered $\mathrm{sp}^{3}$ regions due to the decoration of graphitic lattice by various oxygen groups and lattice defects. The $G$ peak occurs at $1590 \mathrm{~cm}^{-1}$ and corresponds to the bond stretching of $\mathrm{sp}^{2}$ carbons. As evident from Fig. 3a, for a sample of high-quality graphite, the intensity of the $G$ peak is high due to the pristine $\mathrm{sp}^{2}$ arrangement. This is indicative of minimal defects in the honeycomb lattice. In striking contrast, the $\mathrm{G}$ peak intensity for $\mathrm{GO}$ paper is strongly suppressed, indicative of the absence of $\mathrm{sp}^{2}$ hybridizations [13]. This is an expected result since it is well known that the synthesis of GO disrupts the initial crystalline structure as a result of the introduction of strong oxidative agents [14, 83].

While a quick visual inspection of the data in Fig. 3a might tempt one to conclude that $G$ and $D$ peak intensities are identical, a qualitative analysis will help shed better light into this matter. This is typically carried out by measurement of the $\mathrm{I}_{\mathrm{D}} / \mathrm{I}_{\mathrm{G}}$ ratio, an indicator of the degree of defects in the graphitic lattice. The $\mathrm{I}_{\mathrm{D}}$ and $\mathrm{I}_{\mathrm{G}}$ values obtained for graphite, GO paper and all thermally treated $\left(100-600{ }^{\circ} \mathrm{C}\right) \mathrm{GO}$ papers along with the corresponding $\mathrm{I}_{\mathrm{D}} / \mathrm{I}_{\mathrm{G}}$ ratio values are listed in Table 1 . As shown in Fig. $3 b$, the $\mathrm{I}_{\mathrm{D}} / \mathrm{I}_{\mathrm{G}}$ ratio is seen to fluctuate around a base value of about 0.92 for all reduction temperatures ranging from 0 to $500{ }^{\circ} \mathrm{C}$. When the temperature is further raised to $600{ }^{\circ} \mathrm{C}$, there appears to be a sizeable rise in the $I_{D} / I_{G}$ ratio. This rather interesting behavior can be explained as follows. There are two factors that contribute toward the average defects in the GO material. One is the lowering of defects as the oxygenated functional groups are gradually removed from between the graphitic layers. As evident from the FTIR results of Fig. 2, this removal process begins at about $200{ }^{\circ} \mathrm{C}$. The second factor is, a consequence of the first, wherein atoms of carbon are eliminated from the lattice as the carbonyl and carboxyl groups exit the material in the form of $\mathrm{CO}_{2}$ and $\mathrm{CO}$ gases. The removal of atoms in this manner leaves behind crystal vacancies which now tend to increase the average defects. Therefore, at temperatures between 200 and $500{ }^{\circ} \mathrm{C}$, there is no definitive trend in the $\mathrm{I}_{\mathrm{D}} / \mathrm{I}_{\mathrm{G}}$ ratios due to the competition between these two mechanisms. At $600{ }^{\circ} \mathrm{C}$, however, there is a clear indication that the defects caused by vacancies takes over and this reflects as a sizeable increase in the $\mathrm{I}_{\mathrm{D}} / \mathrm{I}_{\mathrm{G}}$ ratio.

It must be emphasized however, that despite the variation in the $I_{D} / I_{G}$ being subtle and any meaningful change occurring only beyond a certain threshold temperature, this does not in any way imply that Raman characterization is not effective in studying the impact of thermal reduction. In fact, it is well known that Raman spectroscopy is one of the most effective methods to characterize graphitic materials [79, 84-86]. Similar difficulties have been previously reported [27, 73], but it must be noted however, that the maximum reduction temperature used in their work was $450{ }^{\circ} \mathrm{C}$, significantly lower than those explored here. Although it would have been very interesting to explore the $\mathrm{I}_{\mathrm{D}} / \mathrm{I}_{\mathrm{G}}$ trend beyond $600{ }^{\circ} \mathrm{C}$, this was not possible as the high 


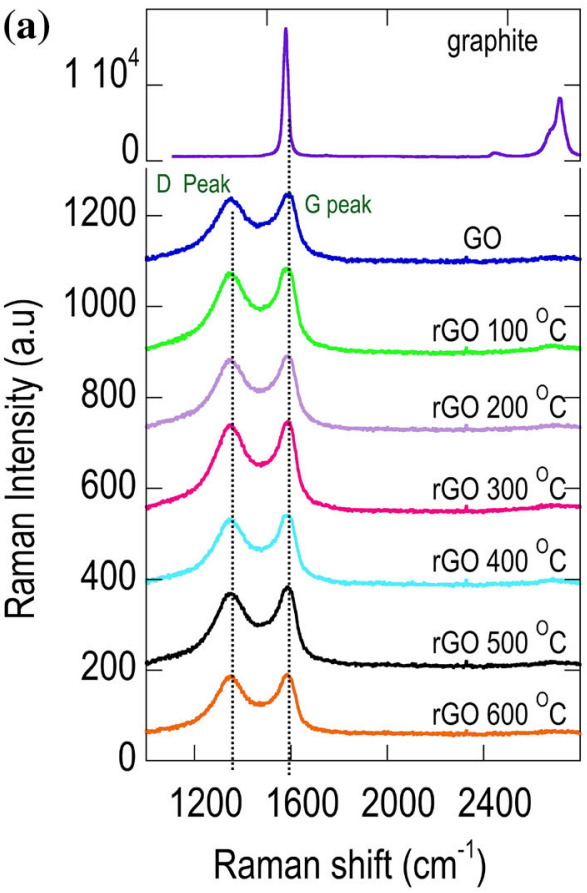

Figure 3 a Raman spectra showing the characteristic $D$ and $G$ peaks of graphite, GO and rGO papers (reduced at $100{ }^{\circ} \mathrm{C}$, $200{ }^{\circ} \mathrm{C}, 300{ }^{\circ} \mathrm{C}, 400{ }^{\circ} \mathrm{C}, 500{ }^{\circ} \mathrm{C}$ and $600{ }^{\circ} \mathrm{C}$ ), b variation of the $\mathrm{I}_{\mathrm{D}} / \mathrm{I}_{\mathrm{G}}$ ratio as a function of reduction temperature. The error bars account for accuracy in the manual measurement of the peak (b)

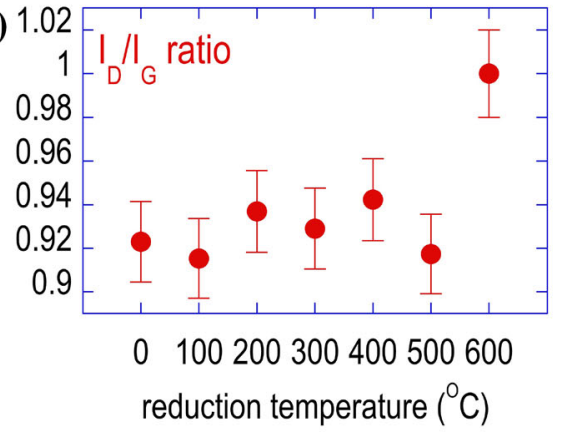

(c)

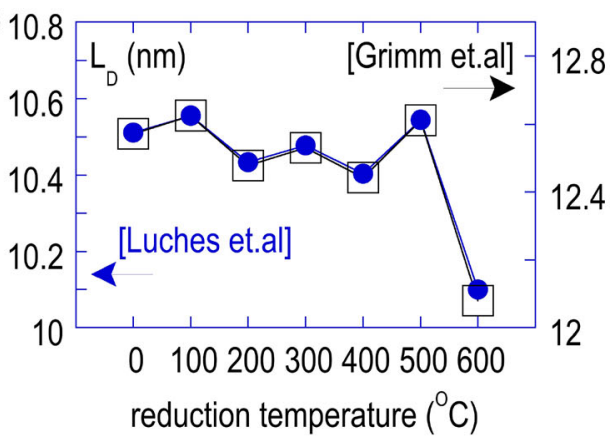

intensity, and c $L_{\mathrm{D}}$ (distance between lattice defects) as a function of reduction temperature calculated using formulae proposed by Lucchese et al [91] (filled blue circles) and Grimm et al. [93] (open black squares).
Table 1 Raw $\mathrm{I}_{\mathrm{D}}, \mathrm{I}_{\mathrm{G}}$, corresponding $\mathrm{I}_{\mathrm{D}} / \mathrm{I}_{\mathrm{G}}$ values, and the calculated distance between lattice defects $\left(L_{\mathrm{D}}\right)$ for the original GO papers and the ones thermally reduced

\begin{tabular}{llllll}
\hline & $\mathrm{I}_{\mathrm{D}}$ & $\mathrm{I}_{\mathrm{G}}$ & $\mathrm{I}_{\mathrm{D}} / \mathrm{I}_{\mathrm{G}}$ & $L_{\mathrm{D}}(\mathrm{nm})$ Luches et al. & $L_{\mathrm{D}}(\mathrm{nm})$ Grimm et al. \\
\hline $\mathrm{GO}$ & 134.666 & 145.888 & 0.923 & 10.512 & 12.572 \\
$\mathrm{rGO} \mathrm{100}{ }^{\circ} \mathrm{C}$ & 166.930 & 182.361 & 0.915 & 10.556 & 12.625 \\
rGO 200 ${ }^{\circ} \mathrm{C}$ & 145.888 & 155.708 & 0.936 & 10.434 & 12.479 \\
rGO 300 ${ }^{\circ} \mathrm{C}$ & 183.763 & 197.791 & 0.929 & 10.478 & 12.531 \\
rGO 400 ${ }^{\circ} \mathrm{C}$ & 137.472 & 145.888 & 0.942 & 10.404 & 12.443 \\
rGO 500 ${ }^{\circ} \mathrm{C}$ & 155.708 & 169.736 & 0.917 & 10.545 & 12.611 \\
rGO 600 ${ }^{\circ} \mathrm{C}$ & 126.249 & 126.250 & 0.999 & 10.100 & 12.079 \\
\hline
\end{tabular}

temperatures would cause the GO paper to become brittle, prohibiting any further meaningful assessment. Perhaps, these regimes can be explored by increasing the thickness of the GO paper, or by employing a different reduction strategy [42, 77] altogether. In the latter approach, the obtained GO papers are sandwiched between the confined space of two Si wafers prior to carrying out the reduction at a high temperature of $800{ }^{\circ} \mathrm{C}$. The confinement was reported to have more effectively preserved the physical structure of the GO papers compared to those that were annealed freely. Nevertheless, with the methodology reported in this work, a reasonable expectation would be that, as the reduction temperatures increases further, the vacancy-type defect density may increase significantly causing a larger rise in the $\mathrm{I}_{\mathrm{D}} / \mathrm{I}_{\mathrm{G}}$ ratio. Unless of course, the defective lattice could be repaired at very high temperatures, in which case the $I_{D} / I_{G}$ ratio would decrease. This has been demonstrated [47, 87-90] but the restoration requires the assistance of a C-source.

Also shown in Table 1 are the $L_{D}$ (distance between lattice defects) values calculated by two different approaches. According to Lucchese et al. [91], as long as $L_{D}$ is greater than $6 \mathrm{~nm}$, it can be estimated from the relation 
$\mathrm{I}_{\mathrm{D}} / \mathrm{I}_{\mathrm{G}}=(102 \pm 2) / L_{\mathrm{D}}^{2}$,

which also in agreement with the Tuinstra-Koenig model [92]. A more sophisticated method involving Raman mapping was employed by Grimm et al. [93] to account for the inhomogeneous nature of rGO. Here, $L_{\mathrm{D}}$ is estimated from the relation

$\mathrm{I}_{\mathrm{D}} / \mathrm{I}_{\mathrm{G}}=4300 /\left(E_{\mathrm{L}}^{4} \cdot L_{\mathrm{D}}^{2}\right)$,

where $E_{\mathrm{L}}$ is the laser energy used. From Fig. 3c, it can be seen that at the processing temperature of $600{ }^{\circ} \mathrm{C}$ there is a significant drop in the $L_{\mathrm{D}}$ value calculated from both methods. This further confirms the defective nature of the rGO paper.

\section{XRD analysis}

XRD is an effective tool for revealing the interplanar spacing (d-spacing) using Bragg's law and the crystalline phases of the material being studied. Figure $4 \mathrm{a}$ shows the XRD results obtained for the GO papers reduced at the various reduction temperatures. The two characteristics peaks of interest here, for comparison sakes, are those of the initial GO paper (2-theta $=11.5^{\circ}$ ) and a pure sample of graphite (2-theta $=26.55^{\circ}$ ). These corresponds to the $<001>$ and $<002>$ crystalline phases of GO and graphite respectively. As the GO papers are thermally reduced, a gradual shift in the dominant crystalline phase is expected as the oxygenated functional groups are systematically eliminated from the GO framework.

From the results shown in the various panels Fig. 4a, a clear shift from $10.32^{\circ}$ to $24.8^{\circ}$ is observed in the major peak of the XRD spectrum as the thermal reduction temperature is increased. At a temperature as low as $200{ }^{\circ} \mathrm{C}$, the prominent $<001>$ phase of GO is suppressed by a lot and the $<002>$ peak is seen to
Figure 4 a XRD traces of graphite, $\mathrm{GO}$ and $\mathrm{GO}$ papers reduced at $100{ }^{\circ} \mathrm{C}, 200{ }^{\circ} \mathrm{C}$, $300{ }^{\circ} \mathrm{C}, 400{ }^{\circ} \mathrm{C}, 500{ }^{\circ} \mathrm{C}$ and $600{ }^{\circ} \mathrm{C}$. The blue dotted line corresponds to graphite with a 2-theta value of $26.5^{\circ}$, b variation of d-spacing values and the major peak position as a function of reduction temperature. The error bars account for uncertainty in determining exact value of 2-theta due to noise in data. The dotted line is the reference d-spacing value of pure graphite c FWHM and $\mathbf{d} L_{\mathrm{C}}$ variation with reduction temperature. The shaded region shows the crystallographic phase dominant in that temperature window. The dotted lines are a guide to the eye showing the overall trend of $L_{\mathrm{c}}$ after neglecting the value calculated at the transition temperature of $300{ }^{\circ} \mathrm{C}$.
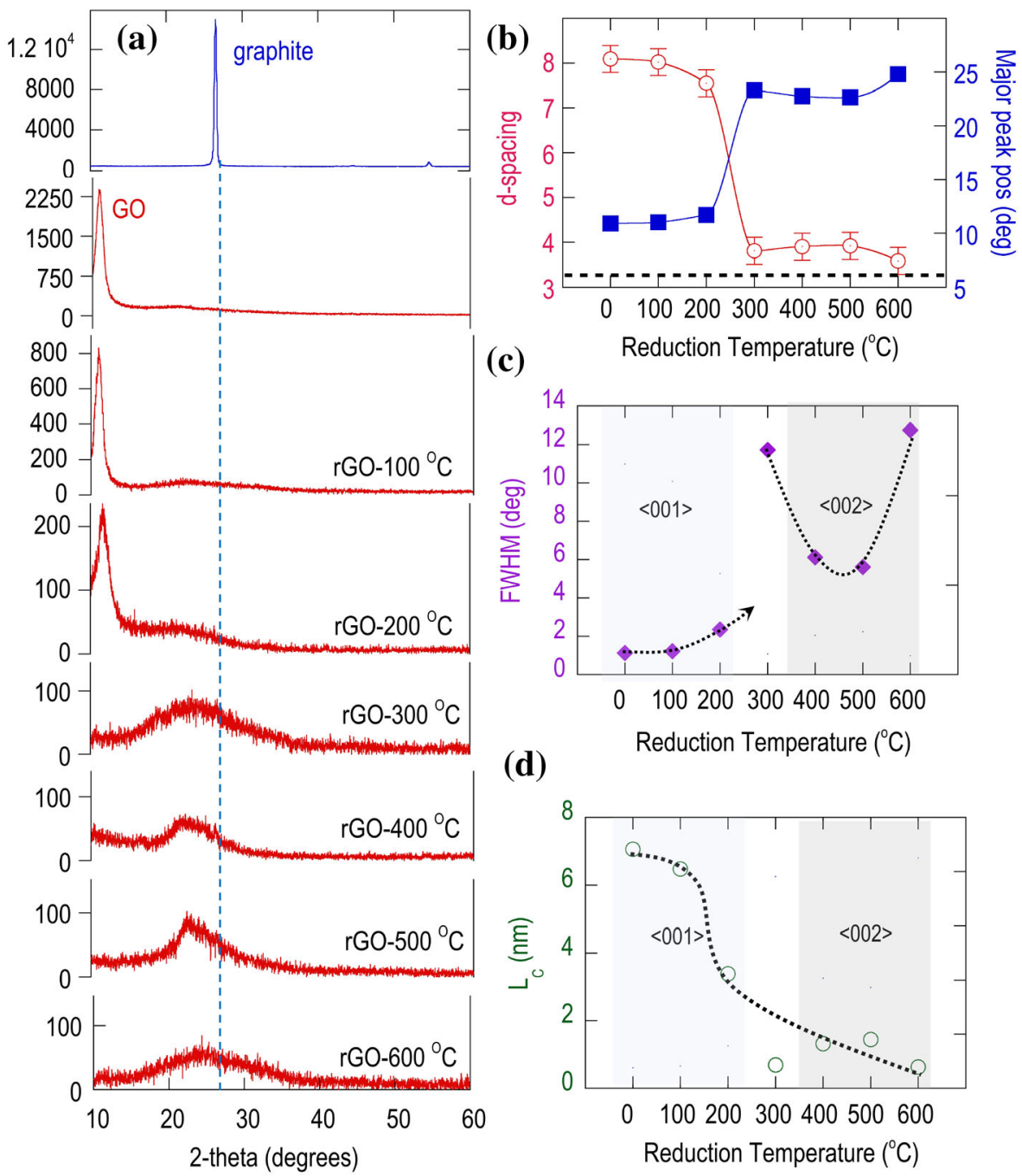

(c)
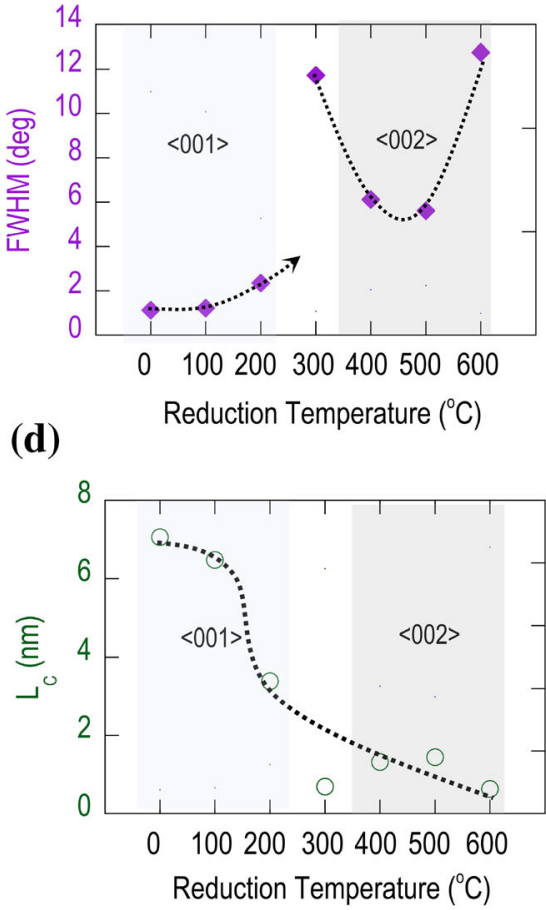
slowly emerge. For a reduction temperature of $300{ }^{\circ} \mathrm{C}$, the $<001>$ peak is completely flattened and a broad $<002>$ begins to develop. This suggests that the onset temperature for effective thermal reduction must lie in the $200-300{ }^{\circ} \mathrm{C}$ range, in good agreement with the results from the Raman analysis of Fig. 2.

As the temperature is increased further to $500{ }^{\circ} \mathrm{C}$, the $<002>$ peak becomes sharpest in intensity. This signifies the improvement of crystallinity as the functional groups are eliminated from the GO lattice. Interestingly, at a reduction temperature of $600{ }^{\circ} \mathrm{C}$, the peak once again broadens, suggesting a loss of crystallinity. This behavior is directly corroborated to the conclusions drawn previously from the $\mathrm{I}_{\mathrm{D}} / \mathrm{I}_{\mathrm{G}}$ analysis of Fig. 3.

The d-spacing and the full-width half-maximum (FWHM) values can be calculated from the information of the major peak's positions and widths. The data presented in Table 2 and Fig. $4 \mathrm{~b}$ reveal that the value of the d-spacing reduces significantly, from 7.6 $\AA$ for the starting GO paper to $3.5 \AA$ for the GO paper thermally reduced at $600{ }^{\circ} \mathrm{C}$. This trend is attributed to the gradual removal to interlayer species, namely the oxygen functional groups [91, 92, 94]. For comparison, the d-spacing value for pure graphite is 3.36 A which agrees with the literature [95]. The quantitate analysis of the FWHM values is shown in Fig. 4c. The FWHM is seen to increase initially as the $<001$ $>$ peak broadens and diminishes in intensity. Once the transition from $<001>$ to $<002>$ phase is underway, the FWHM values show a U-shape trend, which is reflective of an initial improvement in crystallinity followed by a degradation.

The crystal stack height $\left(L_{C}\right)$ values calculated using Scherrer's equation [96]

$L_{C}=0.9 \lambda /($ FWHM. $\cos \theta)$, and the number of graphene layers $\left(N_{C}=L_{C} / d\right)$ are also reported in Table 2 . The variation of $L_{C}$ with reduction temperature (Fig. $4 \mathrm{~d}$ ) shows a systematic lowering as the temperature is increased. The lowering of $L_{C}$ has been attributed to exfoliation of carbon layers caused by the thermal annealing [27, 73].

\section{SEM and elemental analysis}

Morphological changes in the reduction process of GO paper were tracked with the help of FESEM micrographs. The various panels of Fig. 5a capture the evolution of the surface morphology for the GO papers reduced at various reduction temperatures. The original free-standing GO paper appears to be dominated by large wrinkles. This is possibly due to the formation of GO agglomerates during vacuum filtration [44] or from turbulent stacking [77]. The surface morphology of the rGO papers, on the contrary, shows a completely different result. For instance, for reduction temperatures as low as $200{ }^{\circ} \mathrm{C}$, the large wrinkles are seen to be significantly much lesser. With further increase of the reduction temperature to $300{ }^{\circ} \mathrm{C}$ and $400{ }^{\circ} \mathrm{C}$, the wrinkled structures seem to almost disappear. This is because, as more and more functional groups are eliminated from the GO surface, the effects of turbulent stacking (or agglomeration) are reduced, giving the films a much flatter appearance. Despite this flatter appearance however, the SEM micrographs do not reveal a microscopically smooth surface but instead a surface characterized by a mixture of suppressed wrinkles as well as an increasing level of emerging granularity. This apparent microscopic roughness can be seen in the form of sharp edges and can be attributed to the release of functional groups from the surface of the GO paper [46]. As discussed previously in the Raman analysis, the evolution toward the cluttered surface
Table 2 Major peak position, crystal planes identified from the XRD data and calculated d-spacing, FWHM, $L_{\mathrm{C}}$ and $N_{\mathrm{C}}$ values

\begin{tabular}{|c|c|c|c|c|c|c|}
\hline & Major peak pos (deg) & $<\mathrm{hkl}>$ & d-spacing (A) & FWHM (deg) & $L_{\mathrm{C}}(\mathrm{nm})$ & $N_{\mathrm{C}}$ \\
\hline GO & 10.92 & 001 & 8.0924 & 1.13 & 7.06 & 8.72 \\
\hline $\mathrm{rGO} 100^{\circ} \mathrm{C}$ & 11.02 & 001 & 8.0192 & 1.23 & 6.48 & 8.09 \\
\hline $\mathrm{rGO} 200{ }^{\circ} \mathrm{C}$ & 11.71 & 001 & 7.5482 & 2.35 & 3.39 & 4.5 \\
\hline $\mathrm{rGO} 300^{\circ} \mathrm{C}$ & 23.3 & 002 & 3.8132 & 11.73 & 0.69 & 1.81 \\
\hline $\mathrm{rGO} 400{ }^{\circ} \mathrm{C}$ & 22.75 & 002 & 3.9041 & 6.12 & 1.32 & 3.39 \\
\hline $\mathrm{rGO} 500{ }^{\circ} \mathrm{C}$ & 22.65 & 002 & 3.9211 & 5.61 & 1.44 & 3.68 \\
\hline rGO $600{ }^{\circ} \mathrm{C}$ & 24.8 & 002 & 3.5858 & 12.75 & 0.63 & 1.77 \\
\hline Graphite & 26.5 & 002 & 3.3595 & 0.4 & 20.46 & 60.74 \\
\hline
\end{tabular}


(a)

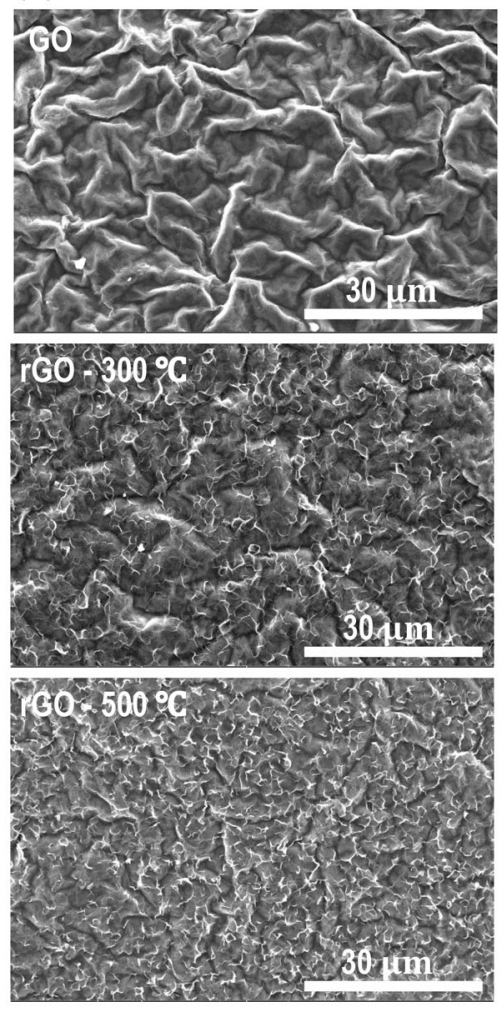

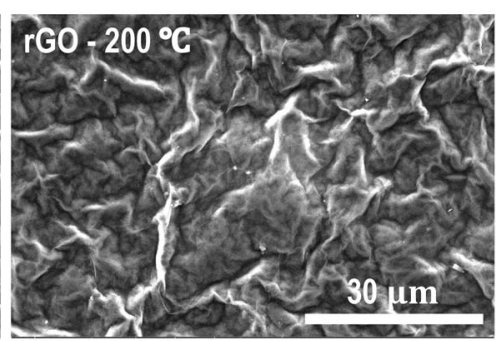
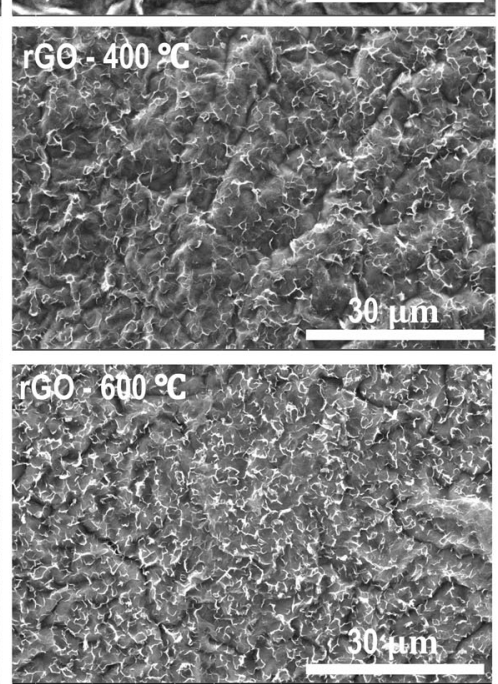

(b)

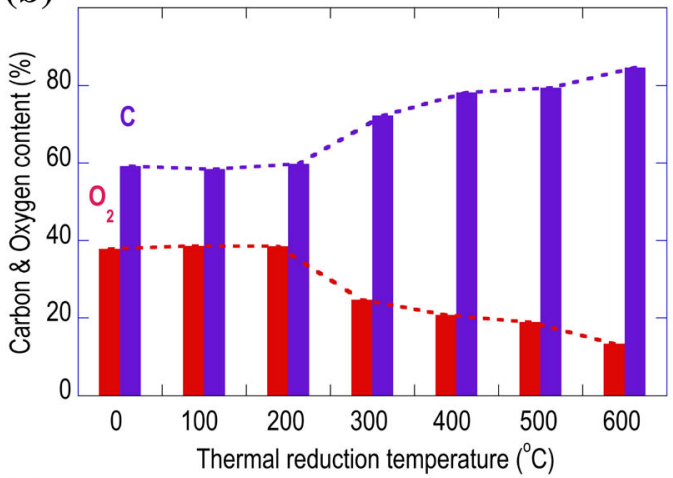

(c)
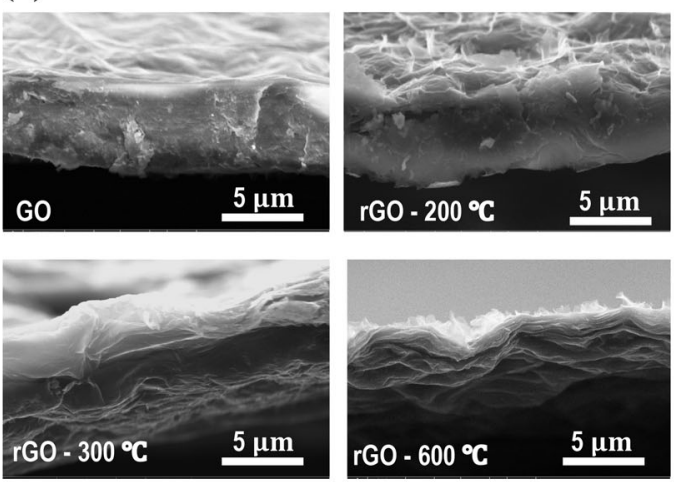

Figure 5 a SEM images of the surface morphology of the original GO paper and rGO papers reduced at $200{ }^{\circ} \mathrm{C}, 300{ }^{\circ} \mathrm{C}, 400{ }^{\circ} \mathrm{C}$, $500{ }^{\circ} \mathrm{C}$ and $600{ }^{\circ} \mathrm{C}$. $\mathrm{b}$ carbon and oxygen content (wt. \%) as a

morphology seen here is once again indicative of competing defect removal mechanisms. At the highest temperatures of $500-600{ }^{\circ} \mathrm{C}$, the SEM micrographs clearly shows a more developed surface, solely dominated by the sharp-edge features. This is strongly suggestive of loss of crystallinity [94] resulting from the propensity of vacancy defect formation caused by $\mathrm{CO}_{2}$ and $\mathrm{CO}$ gases escaping from out of the plane of the GO paper. Since our GO papers are reduced without any physical confinement methods, such as the method reported in Ref [77], the escape of these gases cannot be limited to the in-plane position alone. It is therefore also important to evaluate different strategies for optimizing the reduction efficiency of GO papers and/or obtaining smoother surfaces.

Figure $5 \mathrm{~b}$ shows the elemental analysis performed on the GO and rGO paper samples. Here, the oxygen and carbon content (wt. \%) is plotted as a function of the reduction temperature. The $\mathrm{C}$ and $\mathrm{O}_{2}$ levels remain flat for temperatures up to $200{ }^{\circ} \mathrm{C}$ and then strongly change as the temperature is raised further. function of reduction temperature determined using elemental analysis. c cross-sectional SEM images of the original GO paper and rGO papers reduced at $200{ }^{\circ} \mathrm{C}, 300{ }^{\circ} \mathrm{C}$ and $600{ }^{\circ} \mathrm{C}$.

By $600{ }^{\circ} \mathrm{C}$, the carbon percentage has increased to $85 \%$ from an initial value of $60 \%$ while the oxygen content has proportionately decreased. At $600{ }^{\circ} \mathrm{C}$, the $\mathrm{O}_{2}$ level has dropped to a significantly low value of $13.31 \%$. This value corresponds to the remaining functional groups that are not yet expelled from the GO paper. These could very well be the epoxy groups that are known to be energy-costly for removal [23, 24, 94, 97]. Moreover, further carbon wt. \% enhancement is not expected due to the propensity of vacancy defects, as noted earlier.

The cross-sectional SEM pictures for the original GO paper and those reduced at temperatures of $200{ }^{\circ} \mathrm{C}, 300{ }^{\circ} \mathrm{C}$ and $600{ }^{\circ} \mathrm{C}$ are shown in the panels of Fig. 5c. It has been known from previous works $[46,73,74]$ that the thermal reduction of GO results in exfoliation and layer separation due to the dissociation of the functional groups from the basal planes. This can be understood by comparing the micrographs of the original GO paper, in which no clear layer separation can be seen, and the GO paper thermally reduced at $300{ }^{\circ} \mathrm{C}$ where the individual 
graphene sheets can be discerned. For the GO papers reduced at $600{ }^{\circ} \mathrm{C}$, the separation between layers is seen to increase implying volumetric expansion [73] and more effective removal of the functionalities. From an application standpoint, the layer exfoliation and the resulting stacking is a desired quality for electrode materials due to the high surface area than can be accessed for ion and electron diffusion. Overall, these observations provide important clues to understanding the morphological changes occurring at critical temperatures involved in the reduction process.

\section{AFM}

To shed additional insight on the morphological changes, we have performed AFM scans of the surface of the original GO paper (Fig. 6a) and compared it to the GO paper treated at $400{ }^{\circ} \mathrm{C}$ (Fig. 6b). A clear reduction in surface roughness (RMS) is noticed after thermal reduction. The RMS value drops from 0.73 to $0.44 \mathrm{mV}$, which corresponds to a roughness change of approximately $40 \%$. The resulting smoother surface of the reduced GO sample is attributed to the removal of oxygen functional groups and is consistent with the lowering of wrinkled features seen in the SEM scans. Similar roughness reduction has been reported in the literature [90, 98] albeit with much lower vales than reported here.

\section{Four-point probe measurements}

In this section, we describe detailed electrical measurements performed using a four-point probe measurement setup. Figure $7 \mathrm{a}$ shows the resistance measurements obtained from four batches of vacuum-filtered GO paper samples subject to thermal reduction at temperatures ranging between 100 and $500{ }^{\circ} \mathrm{C}$. The size of the box plot reflects sample to sample variation. The resistance of the GO papers is found to drop very strongly in the temperature range of $200-300{ }^{\circ} \mathrm{C}$. This signifies a transition regime where the GO turns from strongly insulating to strongly conducting. The resistance drops by several orders of magnitude in this temperature window. For higher reduction temperatures, a saturation tendency is observed in the resistance and may point to the fact that further improvement in electrical conduction may be limited. This bodes well with the earlier discussions that have indicated the possibility of a defective GO structure resulting from removal of carbon atoms. Measurements on GO papers reduced at $600{ }^{\circ} \mathrm{C}$ have been avoided due to their semi-brittle nature causing difficulty in taking reliable readings.

Figure $7 \mathrm{~b}$, shows the low-bias current-voltage curves for the different samples studied. Clearly, for temperatures of $300{ }^{\circ} \mathrm{C}, 400{ }^{\circ} \mathrm{C}$ and $500{ }^{\circ} \mathrm{C}$, classic ohmic behavior is obtained as expected for good conductors. On the other hand, the nonlinear curves obtained at $100{ }^{\circ} \mathrm{C}$ and $200{ }^{\circ} \mathrm{C}$, prove that the sample is strongly insulating with very minimal current measured even as the applied voltage is increased by several orders of magnitude. The strong insulating behavior is attributed to the presence of nanometer-scale graphitic domains separated by heavily oxidized regions. The oxidized regions shrink in size as the functional groups are eliminated, resulting in enhanced electrical current $[14,17,83]$. It is further known from temperature-dependent conductivity studies [99, 100], that the electronic transport in $\mathrm{rGO}$ is dominated by variable-range hopping (VRH) and thermal activation (TA) pathways in the bias and temperature regimes explored here.

To further analyze the crossover temperature, a different experiment was performed that involved (a)

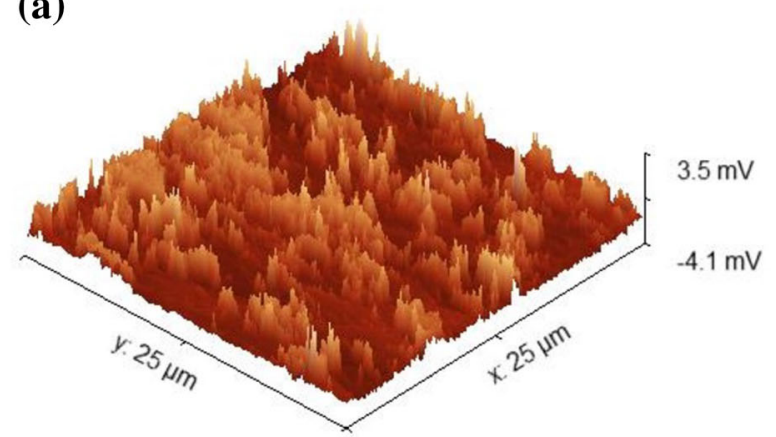

(b)

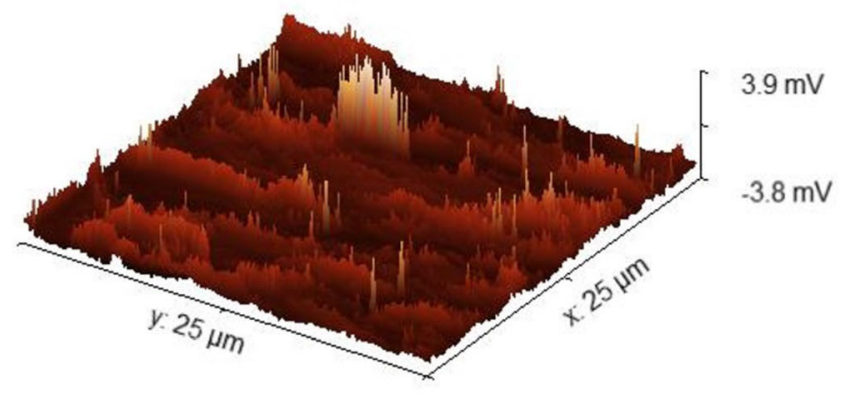

Figure 6 AFM topography scan of a original GO paper and $\mathbf{b}$ rGO paper reduced at $400{ }^{\circ} \mathrm{C}$. 

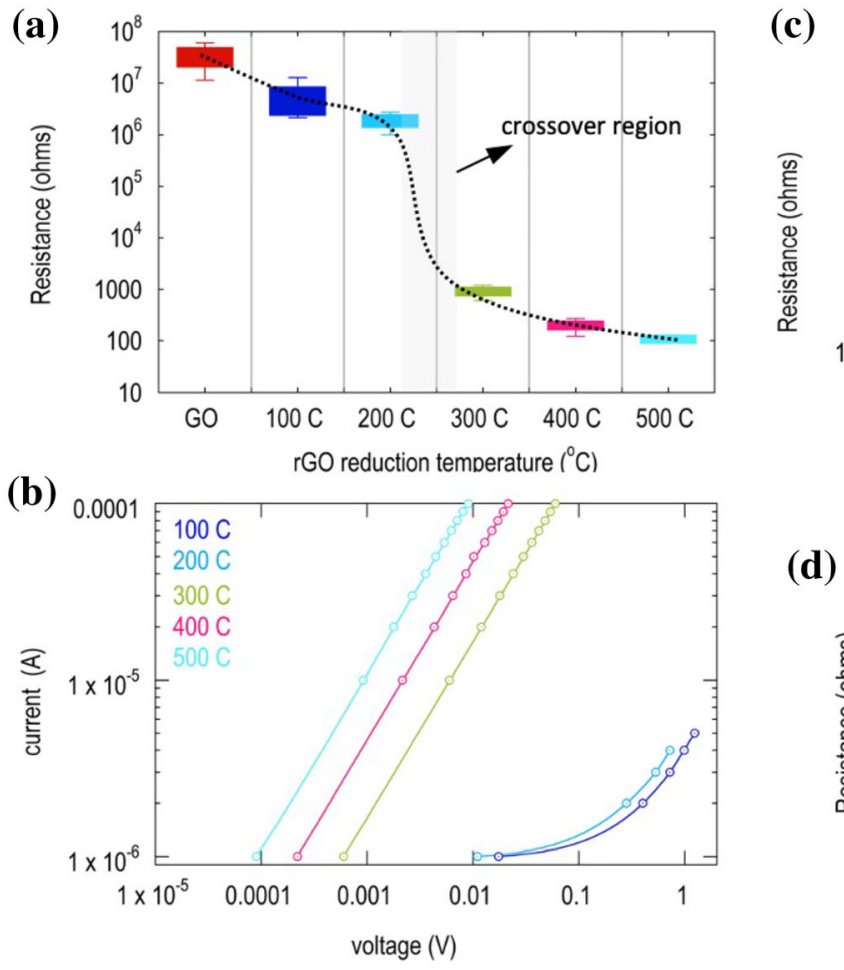

(d)
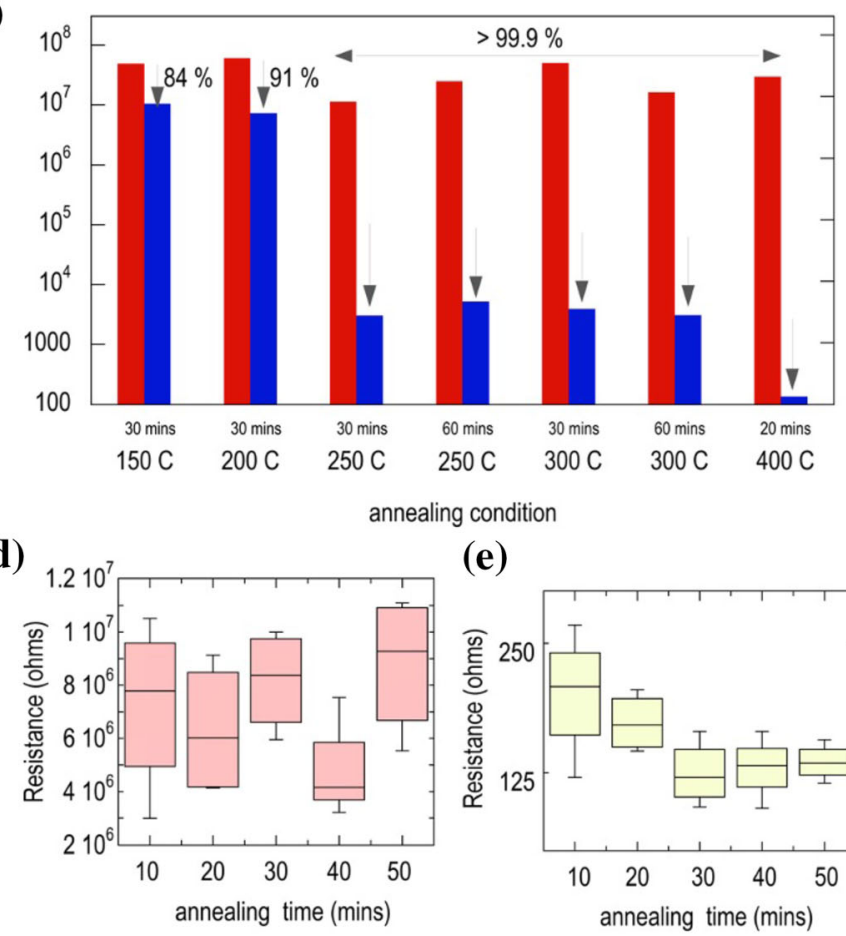

(e)

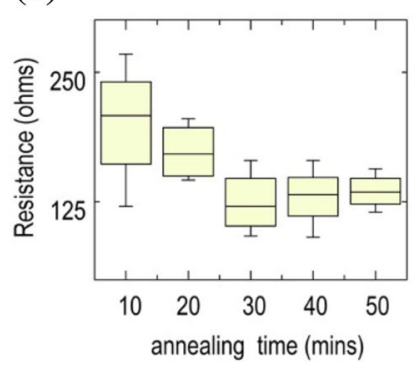

Figure 7 a Box plot of the resistance of four different batches of rGO paper versus reduction temperature. $\mathbf{b}$ I-V curves plotted on a $\log -\log$ variation for a selected batch of samples. c Bar graph

longer reduction times of 30 and $60 \mathrm{~min}$ and the inclusion of GO paper reduced at an intermediate temperature of $250{ }^{\circ} \mathrm{C}$. Clearly, as seen in Fig. 7c, at $200{ }^{\circ} \mathrm{C}$ the resistance change is minimal even as the reduction time was increased to $30 \mathrm{~min}$. On the other hand, at $250{ }^{\circ} \mathrm{C}$, the resistance has dropped by several order of magnitudes constituting a resistance change greater than $99.9 \%$. This implies strong functional group and crystallographic changes already occurring in the GO paper at this temperature. Therefore, from the observations made thus far, we conclude that the transition temperature must lie in between $200{ }^{\circ} \mathrm{C}$ and $250{ }^{\circ} \mathrm{C}$.

To clarify the impact of reduction time on the resistance, we have performed additional measurements as a function of reduction time at $100{ }^{\circ} \mathrm{C}$ and $400{ }^{\circ} \mathrm{C}$. While, an increase of the reduction time shows no systematic variation at $100{ }^{\circ} \mathrm{C}$ (Fig. $7 \mathrm{~d}$ ), at $400{ }^{\circ} \mathrm{C}$, the resistance is seen to systematically drop with reduction time (Fig. 7e). This is an expected result that corresponds to the gradual removal of functional groups with time, as long as the process temperature is high enough to cause reduction. showing magnitude (and percentage) of resistance drop for various reduction conditions. $\mathbf{d}$ Variation of resistance with reduction time at a reduction temperature of $100{ }^{\circ} \mathrm{C}$ (left) and $400{ }^{\circ} \mathrm{C}$ (right).

Overall, these observations correlate very well with the results of the XRD, FTIR and the elemental analysis discussed in the earlier sections.

\section{Conclusions}

In this work, we have conducted systematic studies to understand the effect of thermal reduction temperature on GO papers obtained via a facile vacuum filtration process. To this end, we have obtained and analyzed the FTIR, Raman and XRD patterns of GO papers subject to various reduction temperatures ranging from 100 to $600{ }^{\circ} \mathrm{C}$ and a reduction time of $10 \mathrm{~min}$. The various oxygen functional groups (hydroxy, carbonyl, carboxyl and epoxy) are identified via FTIR and the intensities of these peaks, with the exception of the epoxy group, is found to wash out completely at reduction temperatures of $400{ }^{\circ} \mathrm{C}$. The epoxy peaks are persistent and shows signs of disappearing only above $400{ }^{\circ} \mathrm{C}$, consistent with the known fact that the epoxy groups have a higher dissociation energy. The Raman spectra reveals that the $I_{D} / I_{G}$ ratio fluctuates in the temperature range of 
$100-500{ }^{\circ} \mathrm{C}$ which is reflective of competing contributors to the average defects. One is the lowering of defects due to removal of oxygen functionalities and the other leads to an increase due to the creation of lattice defects as carbon atoms are expelled in the form of $\mathrm{CO}$ and $\mathrm{CO}_{2}$ gases. The contribution from the lattice defects is seen to dominate the average defect at the highest temperature of $600{ }^{\circ} \mathrm{C}$ and is reflected as a sizeable increase of the $\mathrm{I}_{\mathrm{D}} / \mathrm{I}_{\mathrm{G}}$ ratio. The $\mathrm{XRD}$ patterns reveal clear shifting of the crystallographic phase from $<001>$ to $<002>$ as temperature is increased, confirming the reduction of GO to rGO. The $<002>$ peek is sharpest at a temperature of $500{ }^{\circ} \mathrm{C}$ and broadens at $600{ }^{\circ} \mathrm{C}$, in agreement with the Raman analysis.

SEM surface scans revealed that the original GO paper had wrinkles or curvy features which seem to diminish for the GO papers reduced at higher temperatures. This made the surface flatter, which we corroborated with the AFM scans showing a reduction of the rms value by $40 \%$. At the same time, it was observed that the surface of the GO became more granular with sharp edges that were especially pronounced at the highest temperatures. This is indicative of release of functional groups out of the plane of the GO paper. The elemental analysis showed that the carbon content was enhanced by $25 \%$ at the highest reduction temperature of $600{ }^{\circ} \mathrm{C}$. At this temperature, the remaining oxygen content was only 13.31 wt. \% indicative of the effectiveness of higher temperatures in the removal of oxygen functionalities.

Finally, we have analyzed the 4-point probe resistance of four batches of vacuum-filtered GO papers. We identified crossover behavior, characterized by a drop in the resistance by several orders of magnitude, in the temperature range of $200-250{ }^{\circ} \mathrm{C}$. The $\mathrm{I}-\mathrm{V}$ curves of the thermally reduced GO papers exhibited ohmic behavior between 300 and $500{ }^{\circ} \mathrm{C}$, as expected for good conducting materials while the GO papers treated at temperatures below the crossover temperature showed strong insulating behavior with nonlinear I-V. The reduction time was also shown to have a noticeable effect on the average resistance of the samples.

In conclusion, we have presented a comprehensive and corroborative analysis of the evolution of structural and electrical properties of free-standing GO papers as a function of reduction temperature. The crossover between insulating GO and conductive
rGO is found to strongly depend on the reduction temperature and correlates well with the structural and morphological analysis.

\section{Acknowledgements}

This work by King Mongkut's Institute of Technology Ladkrabang has received funding support from the NSRF [Grant No. RE-KRIS/032/64]. RS acknowledges support from Faculty of Science, King Mongkut's Institute of Technology Ladkrabang (grant \# 2563-02-05-35). We would also like to sincerely thank Chawal Sriwong, Department of Chemistry, King Mongkut's Institute of Technology Ladkrabang for helpful discussions and assistance with the preparation of GO solution.

\section{Author contributions}

HR wrote the original manuscript, conducted the four-point-probe measurements, SEM and AFM characterizations and analyzed all the data. $\mathrm{KB}$, TC and KT collaborated on the synthesis of free-standing GO paper. RS supervised the research work, performed the FTIR, Raman and XRD characterizations and reviewed the manuscript.

\section{Declarations}

Conflict of interest The authors declare no competing financial interests or personal relationships that could influence this work.

Open Access This article is licensed under a Creative Commons Attribution 4.0 International License, which permits use, sharing, adaptation, distribution and reproduction in any medium or format, as long as you give appropriate credit to the original author(s) and the source, provide a link to the Creative Commons licence, and indicate if changes were made. The images or other third party material in this article are included in the article's Creative Commons licence, unless indicated otherwise in a credit line to the material. If material is not included in the article's Creative Commons licence and your intended use is not permitted by statutory regulation or exceeds the permitted use, you will need to obtain permission directly from the copyright holder. To view a copy of 
this licence, visit http://creativecommons.org/licen ses/by/4.0/.

\section{References}

[1] Geim AK, Novoselov KS (2007) The rise of graphene. Nat Mater 6:183-191

[2] Novoselov KS, Geim AK, Morozov SV, Jiang D, Zhang Y, Dubonos SV et al (2004) Electric field effect in atomically thin carbon films. Science 306:666-669

[3] Berger C, Wu X, Brown N, Naud C, Li X, Song Z et al (2006) Electronic confinement and coherence in patterned epitaxial graphene. Science 312:1191-1196

[4] Patel RB, Yu C, Chou T, Iqbal Z (2014) Novel synthesis route to graphene using iron nanoparticles. J Mater Res 29:1522-1527

[5] Randviir EP, Brownson DAC, Banks CE (2014) A decade of graphene research: production, applications and outlook. Mater Today 17:426-432

[6] Hummers WS, Offeman RE (1958) Preparation of graphitic oxide. J Am Chem Soc 80:1339

[7] Staudenmaier L (1898) Verfahren zur darstellung der graphitsäure. Ber Dtsch Chem Ges 31:1481-1487

[8] Brodie BC (1859) On the atomic weight of graphite. Philos Trans R Soc London 149:249-259

[9] Su C-Y, Lu A-Y, Xu Y, Chen F-R, Khlobystov AN, Li L-J (2011) High-quality thin graphene films from fast electrochemical exfoliation. ACS Nano 5:2332-2339

[10] Cao J, He P, Mohammed MA, Zhao X, Young RJ, Derby B et al (2017) Two-step electrochemical intercalation and oxidation of graphite for the mass production of graphene oxide. J Am Chem Soc 139:17446-17456

[11] Hofmann U, König E (1937) Untersuchungen über graphitoxyd. Z Anorg Allg Chem 234:311-336

[12] Marcano DC, Kosynkin DV, Berlin JM, Sinitskii A, Sun ZZ, Slesarev A et al (2010) Improved synthesis of graphene oxide. ACS Nano 4:4806-4814

[13] Yu H, Zhang B, Bulin C, Li R, Xing R (2016) High-efficient synthesis of graphene oxide based on improved hummers method. Sci Rep 6:36143

[14] Lerf A, He H, Forster M, Klinowski J (1998) Structure of graphite oxide revisited. J Phys Chem B 102:4477-4482

[15] Bagri A, Mattevi C, Acik M, Chabal YJ, Chhowalla M, Shenoy VB (2010) Structural evolution during the reduction of chemically derived graphene oxide. Nat Chem 2:581-587

[16] Szabó T, Berkesi O, Forgó P, Josepovits K, Sanakis Y, Petridis D et al (2006) Evolution of surface functional groups in a series of progressively oxidized graphite oxides. Chem Mater 18:2740-2749

[17] Chen CM, Zhang Q, Yang MG, Huang CH, Yang YG, Wang MZ (2012) Structural evolution during annealing of thermally reduced graphene nanosheets for application in supercapacitors. Carbon 50:3572-3584

[18] Qiu Y, Collin F, Hurt RH, Külaots I (2016) Thermochemistry and kinetics of graphite oxide exothermic decomposition for safety in large-scale storage and processing. Carbon 96:20-28

[19] Si Y, Samulski ET (2008) Synthesis of water soluble graphene. Nano Lett 8:1679-1682

[20] Gomez-Navarro C, Weitz RT, Bittner AM, Scolari M, Mews A, Burghard $M$ et al (2007) Electronic transport properties of individual chemically reduced graphene oxide sheets. Nano Lett 7:3499-3503

[21] Gilje S, Han S, Wang M, Wang KL, Kaner RB (2007) A chemical route to graphene for device applications. Nano Lett 7:3394-3398

[22] Moon IK, Lee J, Ruoff RS, Lee H (2010) Reduced graphene oxide by chemical graphitization. Nat Commun 1:73

[23] Chua CK, Pumera M (2014) Chemical reduction of graphene oxide: a synthetic chemistry viewpoint. Chem Soc Rev 43:291-312

[24] Pei S, Cheng H-M (2012) The reduction of graphene oxide. Carbon 50:3210-3228

[25] Xu S, Zhang Z, Liu J, Wang Y, Hu J (2017) Facile preparation of reduced graphene by optimizing oxidation condition and further reducing the exfoliated products. J Mater Res 32:383-391

[26] Mao S, Pu H, Chen J (2012) Graphene oxide and its reduction: modeling and experimental progress. RSC Adv 2:2643-2662

[27] Sengupta I, Chakraborty S, Talukdar M, Pal SK, Chakraborty S (2018) Thermal reduction of graphene oxide: how temperature influences purity. J Mater Res 33:4113-4122

[28] Li X, Wang H, Robinson JT, Sanchez H, Diankov G (2009) Simultaneous nitrogen doping and reduction of graphene oxide. J Am Chem Soc 13:15939-15944

[29] Le GTT, Manyam J, Opaprakasit P, Chanlek N, Grisdanurak N, Sreearunothai P (2018) Divergent mechanisms for thermal reduction of graphene oxide and their highly different ion affinities. Diam Relat Mater 89:246-256

[30] Jung I, Dikin DA, Piner RD, Ruoff RS (2008) Tunable electrical conductivity of individual graphene oxide sheets reduced at "low" temperatures. Nano Lett 8:4283-4287

[31] Singh A, Sharma N, Arif M, Katiyar RS (2019) Electrically reduced graphene oxide for photovoltaic application. J Mater Res 34:652-660 
[32] Liu Y, Li P, Wang F, Fang W, Xu Z, Gao W et al (2019) Rapid roll-to-roll production of graphene films using intensive Joule heating. Carbon 155:462-468

[33] Chen W, Yan L, Bangal PR (2010) Preparation of graphene by the rapid and mild thermal reduction of graphene oxide induced by microwaves. Carbon 48:1146-1152

[34] Zhu Y, Murali S, Stoller MD, Velamakanni A, Piner RD, Ruoff RS (2010) Microwave assisted exfoliation and reduction of graphite oxide for ultracapacitors. Carbon 48:2118-2122

[35] Shulga YM, Baskakov SA, Knerelman EI, Davidova GI, Badamshina ER, Shulga NY et al (2014) Carbon nanomaterial produced by microwave exfoliation of graphite oxide: new insights. RSC Adv 4:587-592

[36] Jakhar R, Yap JE, Joshi R (2020) Microwave reduction of graphene oxide. Carbon 170:277-293

[37] Shin HJ, Kim KK, Benayad A, Yoon SM, Park HK, Jung IS et al (2009) Efficient reduction of graphite oxide by sodium borohydride and its effect on electrical conductance. Adv Funct Mater 19:1987-1992

[38] Fernández-Merino MJ, Guardia L, Paredes JI, Villar-Rodil S, Solís-Fernández P, Martínez-Alonso A et al (2010) Vitamin $\mathrm{C}$ is an ideal substitute for hydrazine in the reduction of graphene oxide suspensions. J Phys Chem C 114:6426-6432

[39] Guo H, Wang X-F, Qian Q, Wang F, Xia X (2009) A green approach to the synthesis of graphene nanosheets. ACS Nano 3:2653-2659

[40] Zhang IY, Wang X (2019) An improved process for the graphene preparation via redox potential control. J Mater Res 34:3212-3219

[41] Romero A, Lavin-Lopez MP, Sanchez-Silva L, Valverde JL, Paton-Carrero A (2018) Comparative study of different scalable routes to synthesize graphene oxide and reduced graphene oxide. Mater Chem Phys 203:284-292

[42] Cheng C-M, Huang J-Q, Zhang Q, Gong W-Z, Yang Q-H, Wang M-Z et al (2012) Annealing a graphene oxide film to produce a free standing high conductive graphene film. Carbon 50:659-667

[43] Liu LL, Niu ZQ, Zhang L, Zhou WY, Chen XD, Xie SS (2014) Nanostructured graphene composite papers for highly flexible and foldable supercapacitors. Adv Mater 26(28):4855-4862

[44] Gao J, Liu C, Miao L, Wang X, Chen Y (2016) Freestanding reduced graphene oxide paper with high electrical conductivity. J Electron Mater 45(3):1290-1295

[45] Okhay O, Gonçalves G, Tkach A, Dias C, Ventura J, Fernando $\mathrm{M}$ et al (2016) Thin film versus paper-like reduced graphene oxide: comparative study of structural, electrical, and thermoelectrical properties. J Appl Phys 120:051706
[46] Sadak O, Sundramoorthy AK, Gunasekaran S (2018) Facile and green synthesis of highly conducting graphene paper. Carbon 138:108-117

[47] Li J, Chen X-Y, Lei R-B, Lai J-F, Ma T-M, Li Y (2019) Highly thermally conductive graphene film produced using glucose under low-temperature thermal annealing. J Mater Sci 54:7553-7562. https://doi.org/10.1007/s10853-019-03 406-x

[48] Selvakumar D, Sivaram H, Alsalme A, Alghamdi A, Jayavel R (2019) Freestanding flexible, pure and composite form of reduced graphene oxide paper for ammonia vapor sensing. Sci Rep 9:8749

[49] Karthick R, Chen F (2019) Free-standing graphene paper for energy application: progress and future scenarios. Carbon 150:292-310

[50] Ping YJ, Gong YN, Fu Q, Pan CX (2017) Preparation of three-dimensional graphene foam for high performance supercapacitors. Prog Nat Sci-Mater 27(2):177-181

[51] Liu WW, Li JD, Feng K, Sy A, Liu YS, Lim L et al (2016) Advanced Li-Ion hybrid supercapacitors based on 3D graphene-foam composites. ACS Appl Mater Interfaces 8(39):25941-25953

[52] Li H, Tao Y, Zheng XY, Li ZJ, Liu DH, Xu Z et al (2015) Compressed porous graphene particles for use as supercapacitor electrodes with excellent volumetric performance. Nanoscale 7(44):18459-18463

[53] Jung SM, Mafra DL, Lin CT, Jung HY, Kong J (2015) Controlled porous structures of graphene aerogels and their effect on supercapacitor performance. Nanoscale 7(10):4386-4393

[54] Strong V, Dubin S, El-Kady MF, Lech A, Wang Y, Weiller BH et al (2012) Patterning and electronic tuning of laser scribed graphene for flexible all carbon devices. ACS Nano 6(2):1395-1403

[55] Agresti A, Pescetelli S, Cinà L, Konios D, Kakavelakis G, Kymakis E et al (2016) Efficiency and stability enhancement in perovskite solar cells by inserting lithium-neutralized graphene oxide as electron transporting layer. Adv Funct Mater 26:2686-2694

[56] Liu J, Xu M, Wang B, Zhou Z, Wang L (2017) Fluorescence sensor for detecting protamines based on competitive interactions of polyacrylic acid modified with sodium 4-amino-1-naphthalenesulfonate with protamines and aminated graphene oxide. RSC Adv 7:1432-1438

[57] Singh SB, De M (2020) Thermally exfoliated graphene oxide for hydrogen storage. Mater Chem Phys 239:122102

[58] Chen Y-R, Chiu K-F, Lin HC, Hsieh C-Y, Tsai CB, Chu BTT (2014) The effect of dispersion status with functionalized graphenes for electric double-layer capacitors. Mater Sci Eng B 90:59-65 
[59] Li Z, Gadipelli S, Yang Y, Guo Z (2017) Design of 3D graphene-oxide spheres and their derived hierarchical porous structures for high performance supercapacitors. Small 13:1702474

[60] Lu G, Ocola LE, Chen J (2009) Gas detection using lowtemperature reduced graphene oxide sheets. Appl Phys Lett 94:083111

[61] Kang KM, Kim DW, Ren CE, Cho KM, Kim SJ, Choi JH et al (2017) Selective molecular separation on $\mathrm{Ti}_{3} \mathrm{C}_{2} \mathrm{~T}_{\mathrm{x}}-$ graphene oxide membranes during pressure-driven filtration: comparison with graphene oxide and MXenes. ACS Appl Mater Interfaces 9:44687-44694

[62] Zhu C, Liu P, Mathew AP (2017) Self-assembled TEMPO cellulose nanofibers: graphene oxide-based biohybrids for water purification. ACS Appl Mater Interfaces 9:21048-21058

[63] Wang Y, Chen Y, Lacey SD, Xu L, Xie H, Li T et al (2018) Reduced graphene oxide film with record-high conductivity and mobility. Mater Today 21:186-192

[64] Bandi S, Hastak V, Pavithra CLP, Kashyap S, Singh DK, Luqman $S$ et al (2019) Graphene/chitosan functionalized iron oxide nanoparticles for biomedical applications. J Mater Res 34:3389-3399

[65] Zhao YQ, Zhao DD, Tang PY, Wang YM, Xu CL, Li HL (2012) $\mathrm{MnO}_{2}$ /graphene/ nickel foam composite as high performance supercapacitor electrode via a facile electrochemical deposition strategy. Mater Lett 76:127-130

[66] Zhang ZY, Xiao F, Qian LH, Xiao JW, Wang S, Liu YQ (2014) Facile synthesis of 3D $\mathrm{MnO}_{2}$-graphene and carbon nanotube-graphene composite networks for high-performance, flexible, all-solid-state asymmetric supercapacitors. Adv Energy Mater 4(10):1400064

[67] Huang X, Zeng Z, Fan Z, Liu J, Zhang H (2012) Graphenebased electrodes. Adv Mater 24(45):5979-6004

[68] Ping JF, Wang YX, Fan K, Tang WZ, Wu J, Ying YB (2013) High-performance flexible potentiometric sensing devices using free-standing graphene paper. J Mater Chem B 1(37):4781-4791

[69] Boukhvalov DW, Katsnelson MI (2008) Modeling of graphite oxide. J Am Chem Soc 130:10697-10701

[70] Gao X, Jang J, Nagase S (2010) Hydrazine and thermal reduction of graphene oxide: Reaction mechanisms and design. J Phys Chem C 114:832-842

[71] Qiu Y, Moore S, Hurt R, Külaots I (2017) Influence of external heating rate on the structure and porosity of thermally exfoliated graphite oxide. Carbon 111:651-657

[72] Dao TD, Jeong HM (2015) Graphene prepared by thermal reduction - exfoliation of graphite oxide: effect of raw graphite particle size on the properties of graphite oxide and graphene. Mater Res Bull 70:651-657
[73] Sengupta I, Kumar SSS, Pal SK, Chakraborty S (2020) Characterization of structural transformation of graphene oxide to reduced graphene oxide during thermal annealing. J Mat Res 35(9):1197-1204

[74] Oliviera AEF, Braga GB, Tarley CRT, Pereira AC (2018) Thermally reduced graphene oxide: synthesis, studies and characterization. J Mat Sci. 53:12005-12015. https://doi. org/10.1007/s10853-018-2473-3

[75] Lipatov A, Guinel MJ-F, Muratov DS, Vanyushin VO, Wilson PM, Kolmakov A et al (2018) Low-temperature thermal reduction of graphene oxide: in situ correlative structural, thermal desorption, and electrical transport measurements. Appl Phys Lett 112:053103

[76] Liu S, Hu K, Cerruti M, Barthelat F (2020) Ultra-stiff graphene oxide paper prepared by directed-flow vacuum filtration. Carbon 158:426-434

[77] Chen X, Meng D, Wang B, Li B-W, Li W, Bielawski CW (2016) Rapid thermal decomposition of confined graphene oxide films in air. Carbon 101:71-76

[78] Phrompet C, Sriwong C, Ruttanapun C (2019) Mechanical, dielectric, thermal and antibacterial properties of reduced graphene oxide (rGO)-nanosized C3AH6 cement nanocomposites for smart cement-based materials. Compos Part B 175:107128

[79] Araujo PT, Terrones M, Dresselhaus MS (2012) Defects and impurities in graphene-like materials. Mater Today 15:98-109

[80] Eftekhari A, Garcia H (2017) The necessity of structural irregularities for the chemical applications of graphene. Mater Today Chem 4:1-16

[81] Mattevi C, Eda G, Agnoli S, Miller S, Mkhoyan KA, Celik $O$ et al (2009) Evolution of electrical, chemical, and structural properties of transparent and conducting chemically derived graphene thin films. Adv Funct Mater 19:2577-2583

[82] Kim MC, Hwang GS, Ruoff RS (2009) Epoxide reduction with hydrazine on graphene: a first principles study. J Chem Phys 131:064704

[83] Klinowski J, He H, Forster M, Lerf A (1998) A new structural model for graphite oxide. Chem Phys Lett 287:53-56

[84] Stankovich S, Dikin DA, Piner RD, Kohlhaas KA, Kleinhammes A, Jia Y (2007) Synthesis of graphene-based nanosheets via chemical reduction of exfoliated graphite oxide. Carbon 45:1558-1565

[85] Yang D, Velamakanni A, Bozoklu G, Park S, Stoller M, Piner RD et al (2009) Chemical analysis of graphene oxide films after heat and chemical treatments by X-ray photoelectron and micro-raman spectroscopy. Carbon 47:145-152 
[86] Jorio A, Ferreira EHM, Moutinho MVO, Stavale F, Achete CA, Capaz RB (2010) Measuring disorder in graphene with the G and D bands. Phys Status Solidi B 247:2980-2982

[87] Liang Y, Frisch J, Zhi L, Norouzi-Arasi H, Feng X, Rabe JP et al (2009) Transparent, highly conductive graphene electrodes from acetylene-assisted thermolysis of graphite oxide sheets and nanographene molecules. Nanotechnology 20:434007

[88] Lopez V, Sundaram RS, Gomez-Navarro C, Olea D, Burghard M, Gomez- Herrero J et al (2009) Chemical vapor deposition repair of graphene oxide: a route to highlyconductive graphene monolayers. Adv Mater 21:4683-4686

[89] Ishida T, Miyata Y, Shinoda Y, Kobayashi Y (2016) Anomalous restoration of graphitic layers from graphene oxide in ethanol environment at ultrahigh temperature using solar furnace. Apex 9:25103

[90] De Silva KH, Huang H-H, Joshi R, Yoshimura M (2020) Restoration of the graphitic structure by defect repair during the thermal reduction of graphene oxide. Carbon 166:74-90

[91] Lucchese MM, Stavale F, Ferreira EHM, Vilani C, Moutinho MVO, Capaz RB, Achete CA et al (2010) Quantifying ion-induced defects and Raman relaxation length in graphene. Carbon 48:1592-1597

[92] Tuinstra F, Koenig JL (1970) Raman spectrum of graphite. J Chem Phys 53:1126-1130

[93] Grimm S, Schweiger M, Eigler S, Zaumseil J (2016) Highquality reduced graphene oxide by CVD-assisted annealing. J Phys Chem C 120:3036-3041
[94] Lavin-Lopez MP, Paton-Carrero A, Sanchez-Silva L, Valverde JL, Romero A (2017) Influence of the reduction strategy in the synthesis of reduced graphene oxide. Adv Powder Technol 28:3195-3203

[95] Han JH, Cho KW, Lee K-H, Kim H (1998) Porous graphite matrix for chemical heat pumps. Carbon 36(12):1801-1810

[96] P. Scherrer (1918) Bestimmung der Grösse und der inneren Struktur von Kolloidteilchen mittels Röntgenstrahlen. Kolloidchemie Ein Lehrbuch, 387-409

[97] Sun T, Fabris S, Baroni S (2011) Surface precursors and reaction mechanisms for the thermal reduction of graphene basal surfaces oxidized by atomic oxygen. J Phys Chem C 115(11):4730-4737

[98] Paredes JI, Villar-Rodil S, Solis-Fernandez P, MartinezAlonso A, Tascon JMD (2009) Atomic force and scanning tunneling microscopy imaging of graphene nanosheets derived from graphite oxide. Langmuir 25:5957-5968

[99] Sehrawat P, Abid SS, Islam P (2018) Mishra, reduced graphene oxide based temperature sensor: extraordinary performance governed by lattice dynamics assisted carrier transport. Sens Actuators B 258:424-435

[100] Negishi R, Akabori M, Ito T, Watanabe Y, Kobayashi Y (2016) Band-like transport in highly crystalline graphene oxide films from defective graphene oxides. Sci Rep 6:28936

Publisher's Note Springer Nature remains neutral with regard to jurisdictional claims in published maps and institutional affiliations. 